\title{
Prenatal vitamin D supplementation and infant vitamin D status in Bangladesh
}

\author{
Nandita Perumal ${ }^{1,2}$, Abdullah Al Mahmud ${ }^{3}$, Abdullah H Baqui ${ }^{3,4}$ and Daniel E Roth 1,5,6,* \\ ${ }^{1}$ Centre for Global Child Health, The Hospital for Sick Children, 686 Bay Street, Toronto, ON, Canada, M5G 0A4: \\ ${ }^{2}$ Department of Epidemiology, Dalla Lana School of Public Health, University of Toronto, Toronto, ON, Canada: \\ ${ }^{3}$ Centre for Child and Adolescent Health, International Centre for Diarrhoeal Disease Research, Bangladesh (icddr,b), \\ Mohakhali, Dhaka, Bangladesh: ${ }^{4}$ International Center for Maternal and Newborn Health, Department of \\ International Health, Johns Hopkins Bloomberg School of Public Health, Baltimore, MD, USA: ${ }^{5}$ Division of Paediatric \\ Medicine and Research Institute, The Hospital for Sick Children, 686 Bay Street, Toronto, ON, Canada, M5G 0A4: \\ ${ }^{6}$ Departments of Paediatrics and Nutritional Sciences, University of Toronto, 1 King's College Circle, Toronto, ON, \\ Canada, M5S 1 A8
}

Submitted 11 March 2015: Final revision received 4 September 2015: Accepted 29 September 2015: First published online 6 November 2015

\begin{abstract}
Objective: To determine the effect of prenatal maternal vitamin D supplementation on infant vitamin D status in a tropical region where vitamin D supplementation is not routine.

Design: A prospective observational follow-up of a randomized trial.

Setting: Maternal-child health facility in Dhaka, Bangladesh $\left(23^{\circ} \mathrm{N}\right)$.

Subjects: Infants born to pregnant women ( $n$ 160) randomized to receive $875 \mu \mathrm{g}$ (35000 IU) cholecalciferol (vitamin $\mathrm{D}_{3}$ ) per week (VD) or placebo (PL) during the third trimester were followed from birth until 6 months of age ( $n$ 115). Infant serum 25-hydroxyvitamin D concentration (25(OH)D) was measured at $<1,2,4$ and 6 months of age.

Results: Mean infant $25(\mathrm{OH}) \mathrm{D}$ was higher in the VD $v$. PL group at $<1$ month of age (mean (SD): 80 (20) nmol/l v. $22(18) \mathrm{nmol} / \mathrm{l} ; P<0 \cdot 001)$, but the difference was attenuated by 2 months (52 (19) nmol/1 $v$. 40 (23) nmol/1; $P=0 \cdot 05)$. Groups were similar at 4 months $(P=0 \cdot 40)$ and 6 months $(n 72 ; P=0 \cdot 26)$. In the PL group, mean infant $25(\mathrm{OH}) \mathrm{D}$ increased to $78(95 \% \mathrm{CI} 67,88) \mathrm{nmol} / \mathrm{l}$ by 6 months of age $(n 34)$. $25(\mathrm{OH}) \mathrm{D}$ was higher with infant formula-feeding and higher in summer $v$. winter. Conclusions: Prenatal third-trimester vitamin D supplementation (875 $\mu$ g (35 000 IU)/ week) significantly ameliorated infant vitamin $\mathrm{D}$ status during the neonatal period when the risk of vitamin D deficiency is greatest. Further research is warranted to determine factors that contribute to the rise in $25(\mathrm{OH}) \mathrm{D}$ during the first 6 months of life among breast-fed infants in this setting.
\end{abstract}

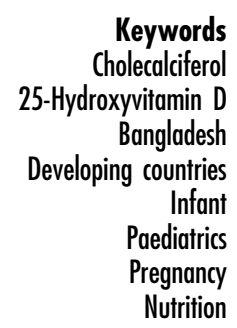

Severe vitamin D deficiency during early infancy is associated with impaired Ca metabolism that may lead to rickets or symptomatic hypocalcaemia ${ }^{(1)}$. Emerging evidence suggests that mild-to-moderate vitamin D deficits in infancy may cause adverse longer-term health outcomes $^{(2,3)}$. In countries at northerly latitudes (e.g. Canada, USA, UK), fortification of infant formula and recommendations in favour of routine vitamin D supplementation of breast-fed infants are mandated to prevent rickets ${ }^{(4-8)}$. In countries closer to the equator, where cutaneous vitamin D synthesis is expected year-round, infant vitamin D status may be adequate in the absence of supplementation ${ }^{(7,8)}$. However, poor vitamin D status marked by low serum 25-hydroxyvitamin D concentrations (25(OH)D) has been observed among pregnant women and young infants in India $^{(9,10)}$, Bangladesh $^{(11,12)}$ and Pakistan ${ }^{(13,14)}$, leading to calls for routine vitamin D supplementation for breast-fed infants in South Asia ${ }^{(15)}$.

Maternal vitamin D status is believed to influence infant status, particularly during the first 2 months of life ${ }^{(16)}$. Prenatal maternal vitamin D supplementation is therefore a potential strategy to promote early infant vitamin D sufficiency ${ }^{(14)}$. However, no previous randomized trials have established the effect of maternal prenatal vitamin D intake on infant vitamin D status beyond the first week of life $^{(17,18)}$ or independent of infant supplementation ${ }^{(19)}$. In a randomized double-blind placebo-controlled trial of prenatal vitamin D supplementation (875 $\mu \mathrm{g}(35000 \mathrm{IU}) /$ week) in 
Dhaka, Bangladesh ${ }^{(3,12)}$, infants were followed prospectively without prescribed postnatal vitamin D supplementation according to practices typical of tropical regions. In the present study, we aimed to: (i) assess the effect of prenatal maternal vitamin D supplementation on infant 25(OH)D up to 6 months of age; and (ii) describe the association of postnatal factors with the rise in infant $25(\mathrm{OH}) \mathrm{D}$ from birth to 6 months of age, which has been observed in multiple settings ${ }^{(8,19-22)}$.

\section{Methods}

The Antenatal Vitamin D in Dhaka (AViDD) trial $\left(23^{\circ} \mathrm{N}\right)$ was previously described in detail ${ }^{(3,12)}$. Briefly, 160 pregnant Bangladeshi women between 18 and 35 years of age, with no known pregnancy-related complications, were randomized, using a computer-generated randomization list with 1:1 allocation, at 26 to 29 weeks' gestation to receive $875 \mu \mathrm{g}$ (35000 IU) cholecalciferol (vitamin $\mathrm{D}_{3}$ ) per week (VD) or placebo (PL) until delivery. Safety and dosing considerations for vitamin D supplementation in pregnancy have been described previously ${ }^{(12,23)}$. Infants were enrolled in a prospective observational follow-up. The study included data from birth (October 2010 to April 2011) to 6 months of age (March to September 2011); however, infant blood specimen collection began in December 2010. In accordance with standards of care in Bangladesh, neither mothers nor infants were provided with vitamin D supplementation in the postpartum/ postnatal period. Written consent was obtained at the time of trial enrolment and again at the first postnatal visit. The AViDD trial was registered at ClinicalTrials.gov (NCT01126528).

\section{Data collection}

Maternal characteristics and prenatal dietary intake were assessed at weekly prenatal home visits. Infant health status, feeding patterns and swaddling practices were based on maternal report and ascertained using standardized questionnaires at 1, 4, 8 or 16 weeks (randomly assigned) and 24 weeks of age. Infant venous blood collection was scheduled at 3 or $5 \mathrm{~d}, 8$ or 16 weeks and 24 weeks of age (total of three scheduled blood samples). Maternal blood collection was scheduled at delivery (with cord blood) and at 8 or 16 weeks postpartum in conjunction with the scheduled infant sample. Serum $25(\mathrm{OH}) \mathrm{D}$ was measured by HPLC-tandem MS (LC-MS/MS) at The Hospital for Sick Children in Toronto, as previously described ${ }^{(12)}$. Vitamin D status was based on the following conventional $25(\mathrm{OH}) \mathrm{D}$ cut-off points: 30, 50 and $80 \mathrm{nmol} / \mathrm{l}$.

\section{Statistical analysis}

The primary outcome was infant $25(\mathrm{OH}) \mathrm{D}$ up to 6 months of age using all available data (referred to as the full sample' analysis) using an intent-to-treat approach. To address aim \#1, we conducted cross-sectional comparisons of infant and maternal $25(\mathrm{OH}) \mathrm{D}$ in the VD and PL groups within specific age ranges, using bootstrapped linear regressions. Bootstrapping was used to obtain more reliable estimates of the standard errors in the small cross-sectional samples. The $\chi^{2}$ test or Fisher's exact test was used to compare the proportions of infants/mothers in vitamin D status categories. Sensitivity analyses limited to infants with at least three postnatal $25(\mathrm{OH}) \mathrm{D}$ measurements yielded the same inferences as analysis of the full data set (not shown). Longitudinal analyses to describe the association between infant $25(\mathrm{OH}) \mathrm{D}$ with age in the VD and PL groups were performed using piecewise linear regression splines with knots at 2 and 4 months of age (corresponding to the blood collection schedule) to accommodate the non-linear pattern of change in the VD group. To account for within-person correlation of repeated measures, generalized estimating equations (GEE) with robust standard errors and exchangeable correlation were used. We also explored associations between infant 25(OH)D and either maternal $25(\mathrm{OH}) \mathrm{D}$ concentration at delivery (a marker of maternal prenatal 25(OH)D status) or cord 25(OH)D (an indicator of fetal vitamin D stores), to extend the findings of the VD-PL group comparisons. Associations between postpartum maternal 25(OH)D and infant vitamin D status were analysed in a similar fashion, but in a smaller subgroup for whom data were available ( $n$ 98).

To address aim \#2 (identification of postnatal factors associated with infant $25(\mathrm{OH}) \mathrm{D}$ from birth to 6 months of age), we analysed a subset of infant $25(\mathrm{OH}) \mathrm{D}$ data that we considered to be relatively unaffected by maternal vitamin D supplementation (referred to as the 'subset' analysis); this included all PL data plus VD data at 4 and 6 months of age (102 infants; 187 observations; see online supplementary material, Supplemental Fig. 1). Using the entire data set would have required the use of three-way interaction terms among the covariate of interest, age and supplementation group, thereby adding unnecessary complexity to the model at the expense of interpretability and parsimony. We focused on the following hypothesized postnatal determinants of infant vitamin D status: age; season (calendar day on which serum was collected, as a continuous variable); maternal postpartum $25(\mathrm{OH}) \mathrm{D}$; and infant dietary patterns. Exclusive breast-feeding and infant formula use were included as time-varying covariates. Animal-source complementary foods were infrequently consumed at $<6$ months and thus not analysed.

We considered potential confounders (maternal height, parity, gravidity, maternal age and maternal education level) and tested for interaction between age and other postnatal determinants of infant $25(\mathrm{OH}) \mathrm{D}$ (see online supplementary material, Supplemental Fig. 2). For analyses addressing aim \#2 ('subset' analyses), we performed linear regression with infant $25(\mathrm{OH}) \mathrm{D}$ as the outcome variable, using GEE to account for within-infant correlation 
Table 1 Infant demographic, lifestyle and dietary characteristics, by supplementation group. Antenatal Vitamin D in Dhaka (AViDD) trial $\left(23^{\circ} \mathrm{N}\right)$, Bangladesh

\begin{tabular}{|c|c|c|c|c|c|c|c|c|}
\hline \multirow[b]{3}{*}{ Characteristic } & \multirow{2}{*}{\multicolumn{2}{|c|}{ Placebo† ( $n 55)$}} & \multicolumn{4}{|c|}{ Vitamin D } & \multirow[b]{3}{*}{$P \S$} & \multirow[b]{3}{*}{$P \|$} \\
\hline & & & \multicolumn{2}{|c|}{ All $(n 60)$} & \multicolumn{2}{|c|}{ Subset ( $n$ 47) } & & \\
\hline & $\begin{array}{l}\% \text { or } \\
\text { Mean }\end{array}$ & $\begin{array}{c}n, n / N \text { or } \\
\text { SD }\end{array}$ & $\begin{array}{l}\% \text { or } \\
\text { Mean }\end{array}$ & $\begin{array}{c}n, n / N \text { or } \\
\text { SD }\end{array}$ & $\begin{array}{l}\% \text { or } \\
\text { Mean }\end{array}$ & $\begin{array}{c}n, n / N \text { or } \\
\text { SD }\end{array}$ & & \\
\hline \multicolumn{9}{|l|}{ Sex, $\%$ and $n$} \\
\hline Females & 51 & 28 & 56 & 34 & 53 & 25 & \multirow[t]{2}{*}{0.36} & \multirow[t]{2}{*}{0.54} \\
\hline Males & 49 & 27 & 43 & 26 & 47 & 22 & & \\
\hline \multicolumn{9}{|l|}{ Gestational age at birth, $\%$ and $n$} \\
\hline Preterm ( 34 to $<37$ weeks) & 24 & 13 & 12 & 7 & 15 & 7 & \multirow[t]{2}{*}{0.33} & \multirow[t]{2}{*}{0.09} \\
\hline Term ( $\geq 37$ weeks) & 76 & 42 & 88 & 53 & 85 & 40 & & \\
\hline \multicolumn{9}{|l|}{ Season at birth, \% and $n$} \\
\hline October-November & 24 & 13 & 32 & 19 & 23 & 11 & \multirow{3}{*}{0.04} & \multirow[t]{3}{*}{0.46} \\
\hline December-February & 56 & 31 & 45 & 27 & 49 & 23 & & \\
\hline March-April & 20 & 11 & 23 & 14 & 28 & 13 & & \\
\hline \multicolumn{9}{|l|}{ Infant anthropometry, mean and SD } \\
\hline Birth weight $(\mathrm{kg})$ & $2 \cdot 8$ & 0.4 & 2.9 & 0.5 & 2.9 & 0.5 & 1.00 & 0.71 \\
\hline Length at birth $(\mathrm{cm})$ & 48.1 & $2 \cdot 2$ & 48.5 & 1.8 & 48.5 & 1.9 & 0.78 & 0.28 \\
\hline Initiated breast-feeding within $1 \mathrm{~h}$ of birth, $\%$ and $n$ & 95 & 52 & 95 & 57 & 94 & 44 & 0.35 & 0.91 \\
\hline \multicolumn{9}{|l|}{ Exclusively breast-fed $\rrbracket, \dagger †, \%$ and $n$} \\
\hline 2 months visit & $\begin{array}{l}10 \\
56\end{array}$ & $\begin{array}{l}39 / 51 \\
14 / 25\end{array}$ & $\begin{array}{l}15 \\
60\end{array}$ & $\begin{array}{l}39 / 52 \\
18 / 30\end{array}$ & 58 & $\begin{array}{l}30 / 39 \\
11 / 19\end{array}$ & 0.76 & $\begin{array}{l}0.86 \\
0.77\end{array}$ \\
\hline 4 months visit & 66 & $19 / 29$ & 55 & $16 / 29$ & 55 & $16 / 29$ & 1.00 & 0.42 \\
\hline 6 months visit & 28 & $14 / 50$ & 36 & $18 / 50$ & 36 & $15 / 42$ & 1.00 & 0.39 \\
\hline \multicolumn{9}{|l|}{ 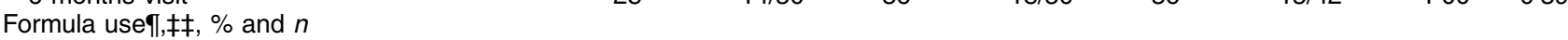 } \\
\hline 1 month visit & 18 & $9 / 51$ & 17 & $9 / 52$ & 13 & $5 / 39$ & 0.20 & 0.96 \\
\hline 2 months visit & 24 & $6 / 25$ & 23 & $7 / 30$ & 21 & $4 / 19$ & 0.70 & 0.95 \\
\hline 4 months visit & 24 & $7 / 29$ & 24 & $7 / 29$ & 24 & $7 / 29$ & 1.00 & 1.00 \\
\hline 6 months visit & 48 & $24 / 50$ & 42 & $21 / 50$ & 40 & $17 / 42$ & 0.71 & 0.55 \\
\hline \multicolumn{9}{|l|}{ Animal-source foods $\uparrow, \S \S, \%$ and $n / N$} \\
\hline 1 month visit & 0 & $0 / 51$ & 0 & $0 / 52$ & 0 & $0 / 39$ & - & - \\
\hline 2 months visit & 0 & $0 / 25$ & 7 & $2 / 30$ & 11 & $2 / 19$ & 0.52 & 0.19 \\
\hline 4 months visit & 0 & $0 / 29$ & 7 & $2 / 29$ & 7 & $2 / 29$ & 1.00 & 0.15 \\
\hline 6 months visit & 16 & $8 / 50$ & 16 & $8 / 50$ & 19 & $8 / 42$ & 0.32 & 1.00 \\
\hline \multicolumn{9}{|c|}{ Usually or always swaddled outside the home, \% and $n / N$} \\
\hline 1 month visit & 98 & $50 / 51$ & 98 & $50 / 51$ & 97 & $37 / 38$ & 1.00 & 1.00 \\
\hline 2 months visit & 68 & $17 / 25$ & 70 & $21 / 30$ & 74 & $14 / 19$ & 0.69 & 0.87 \\
\hline 4 months visit & 24 & $7 / 29$ & 31 & $9 / 29$ & 31 & $9 / 29$ & 1.00 & 0.56 \\
\hline 6 months visit & 6 & $3 / 50$ & 4 & $2 / 50$ & 2 & $1 / 42$ & 0.30 & 0.65 \\
\hline \multicolumn{9}{|c|}{ Expressed preference to expose infant to sunlight, \% and $n / N$} \\
\hline 1 month visit & 92 & $47 / 51$ & 94 & $47 / 50$ & 92 & $34 / 37$ & 0.56 & 0.72 \\
\hline 2 months visit & 64 & $16 / 25$ & 60 & $18 / 30$ & 58 & $11 / 19$ & 1.00 & 0.76 \\
\hline 4 months visit & 59 & $17 / 29$ & 79 & $23 / 29$ & 79 & $23 / 29$ & 1.00 & 0.09 \\
\hline 6 months visit & 90 & $45 / 50$ & 68 & $34 / 50$ & 67 & $28 / 42$ & 1.00 & 0.01 \\
\hline
\end{tabular}

†There was one set of twins in the placebo group, hence, there were fifty-five infants born to fifty-four mothers in the placebo group.

$\ddagger$ Vitamin D 'all' group included data for all infants with any 25-hydroxyvitamin $D(25(\mathrm{OH}) \mathrm{D})$ available in the first 6 months of life. The 'subset' excluded data for thirteen infants who did not contribute $25(\mathrm{OH}) \mathrm{D}$ data at or beyond 4 months.

$\S P$ values for differences between 'all' and 'subset' vitamin $D$ groups were based on $x^{2}$ and Fisher's exact tests for proportions or linear regression for differences in means.

$\| P$ values for differences between placebo and 'all' vitamin D groups were based on $\chi^{2}$ and Fisher's exact tests for proportions or linear regression for differences in means.

TSpecified postnatal visits: 1 month ( 2 to $40 \mathrm{~d}$ ), 2 months (46 to $81 \mathrm{~d}$ ), 4 months ( 84 to $138 \mathrm{~d}$ ) and 6 months (168 to $203 \mathrm{~d}$ ).

††Exclusive breast-feeding was defined as reported breast-feeding in the past $24 \mathrm{~h}$ (yes/no) and a lack of formula or complementary foods previously ever reportedly fed to the infant.

$\ddagger \ddagger$ Data on recent formula use (yes/no) was available for $n 98$ ( $n 47$ in the placebo group and $n 51$ in the vitamin D group). Infant 'formula' type often unspecified by caregiver; may include powdered fortified milk beverages not intended for infants.

$\S \S R e p o r t e d$ infant consumption of animal-source foods (yes/no), including fish, animal milk (other than 'infant formula'), egg, meat or liver.

of $25(\mathrm{OH}) \mathrm{D}$ at different ages. The association between infant $25(\mathrm{OH}) \mathrm{D}$ and age was essentially linear, hence spline functions were not required. In a forward-selection model building process, explanatory variables were included in the multivariable GEE model if they were associated with the dependent variable with a $P$ value $<0.20$ in age-adjusted analyses. To explore whether the age-related rise in $25(\mathrm{OH}) \mathrm{D}$ was attributable to exogenous vitamin D intake, we also performed stratified analyses in which we compared the $25(\mathrm{OH}) \mathrm{D}-$ age slope in the context of exclusive breast-feeding ( $v$. not exclusive breast-feeding) or reported recent formula use ( $v$. no recent formula use) using the 'subset' analysis sample. Significance was assessed at a two-sided $\alpha$ level $<0 \cdot 05$. All analyses were conducted using the statistical software package Stata versions $12 \cdot 1$ and $13 \cdot 1$. 
Table 2 Infant vitamin D status (mean serum 25-hydroxyvitamin D concentration $(25(\mathrm{OH}) \mathrm{D})$ and vitamin $\mathrm{D}$ categories) during the first 6 months of life, by supplementation group. Antenatal Vitamin D in Dhaka (AViDD) trial $\left(23^{\circ} \mathrm{N}\right)$, Bangladesh

\begin{tabular}{|c|c|c|c|c|c|c|c|}
\hline \multirow[b]{2}{*}{ Serum $25(\mathrm{OH}) \mathrm{D}$} & \multicolumn{3}{|c|}{ Placebo } & \multicolumn{3}{|c|}{ Vitamin D } & \multirow[b]{2}{*}{$P \dagger$} \\
\hline & Mean or $\%$ & SD or $n$ & $95 \% \mathrm{Cl}$ & Mean or $\%$ & SD or $n$ & $95 \% \mathrm{Cl}$ & \\
\hline$<1$ month $\ddagger$,§,॥ $(\mathrm{nmol} / \mathrm{l})$ & & $n 34$ & & & $n 30$ & & \\
\hline Average & $22 \cdot 0$ & $17 \cdot 6$ & $16 \cdot 2,27 \cdot 8$ & $80 \cdot 1$ & $20 \cdot 3$ & $73 \cdot 6,86 \cdot 6$ & $<0.001$ \\
\hline$<30 \mathrm{nmol} / \mathrm{l}$ & 79 & 27 & 62,90 & 0 & 0 & - & $<0.001$ \\
\hline $30-49 \mathrm{nmol} / \mathrm{l}$ & 18 & 6 & 8,35 & 3 & 1 & 0,22 & \\
\hline $50-79 \mathrm{nmol} / \mathrm{l}$ & 3 & 1 & 0,20 & 60 & 18 & 41,77 & \\
\hline$\geq 80 \mathrm{nmol} / \mathrm{l}$ & 0 & 0 & - & 37 & 11 & 21,56 & \\
\hline 2 months $\ddagger$, $(\mathrm{nmol} / \mathrm{l})$ & & $n 23$ & & & $n 25$ & & \\
\hline Average & $40 \cdot 2$ & 23.2 & $30 \cdot 1,50 \cdot 2$ & 51.8 & 18.6 & $44.1,59.5$ & 0.05 \\
\hline$<30 \mathrm{nmol} / \mathrm{l}$ & 39 & 9 & 21,61 & 16 & 4 & 6,38 & 0.23 \\
\hline $30-49 \mathrm{nmol} / \mathrm{l}$ & 22 & 5 & 9,45 & 28 & 7 & 13,50 & \\
\hline $50-79 \mathrm{nmol} / \mathrm{l}$ & 30 & 7 & 14,54 & 52 & 13 & 32,72 & \\
\hline$\geq 80 \mathrm{nmol} / \mathrm{l}$ & 9 & 2 & 2,31 & 4 & 1 & 0,26 & \\
\hline 4 months $\ddagger, \mathbb{( n m o l} / \mathrm{l})$ & & $n 25$ & & & $n 29$ & & \\
\hline Average & 61.2 & $29 \cdot 3$ & $49.1,73.3$ & $66 \cdot 9$ & 19.5 & $59.4,74.3$ & 0.40 \\
\hline$<30 \mathrm{nmol} / \mathrm{l}$ & 16 & 4 & 6,38 & 0 & 0 & - & $0 \cdot 10$ \\
\hline $30-49 \mathrm{nmol} / \mathrm{l}$ & 16 & 4 & 6,38 & 28 & 8 & 14,48 & \\
\hline $50-79 \mathrm{nmol} / \mathrm{l}$ & 48 & 12 & 28,68 & 41 & 12 & 24,61 & \\
\hline$\geq 80 \mathrm{nmol} / /$ & 20 & 5 & 8,42 & 31 & 9 & 16,51 & \\
\hline 6 months $\ddagger, \|(\mathrm{nmol} / \mathrm{l})$ & & $n 34$ & & & $n 38$ & & \\
\hline Average & 77.5 & $29 \cdot 1$ & $67 \cdot 1,87 \cdot 6$ & $70 \cdot 4$ & 24.3 & $62 \cdot 4,78 \cdot 4$ & 0.26 \\
\hline$<30 \mathrm{nmol} / \mathrm{l}$ & 6 & 2 & 1,22 & 5 & 2 & 1,20 & 0.82 \\
\hline $30-49 \mathrm{nmol} / \mathrm{l}$ & 15 & 5 & 6,32 & 16 & 6 & 7,32 & \\
\hline $50-79 \mathrm{nmol} / \mathrm{l}$ & 32 & 11 & 18,50 & 42 & 16 & 27,59 & \\
\hline$\geq 80 \mathrm{nmol} / \mathrm{l}$ & 47 & 16 & 30,64 & 37 & 14 & 23,54 & \\
\hline
\end{tabular}

$\dagger P$ values from linear regression with bootstrapped standard errors using 10000 repetitions for comparisons of continuous variables and $x^{2}$ test or Fischer's exact test for proportions.

$\ddagger$ Serum $25(\mathrm{OH}) \mathrm{D}$ presented as mean and SD in the first line labelled 'Average' and as \%, $n$ and $95 \% \mathrm{Cl}$ for categories. The number of measurements in each age category varied as not all infants contributed data at every time point.

§For infants with $25(\mathrm{OH}) \mathrm{D}$ measured at $<1$ month, sixty-seven measurements were within 1 week of birth, eight were measured within 2 weeks and five infant $25(\mathrm{OH}) \mathrm{D}$ values were measured within $30 \mathrm{~d}$.

IIRepeat 25(OH)D measurements (up to three) were available for three infants in the placebo group and seven infants in the vitamin D group. Generalized estimating equations (GEE) with exchangeable correlation and robust standard errors were used account for repeated observations when assessing betweengroup differences (placebo group, thirty-eight observations; vitamin D group, forty observations). An average of multiple 25(OH)D data points was used for categorization of vitamin D status.

IIInfant age range at postnatal visits: 2 months (54 to $81 \mathrm{~d}$ ), 4 months ( 84 to $138 \mathrm{~d}$ ) and 6 months (168 to $203 \mathrm{~d}$ ).

\section{Results}

Of 160 women enrolled in the AViDD trial, 114 (71\%) had at least one infant $25(\mathrm{OH}) \mathrm{D}$ value available during the 6 months postnatal study period (115 infants, including one set of twins: $n 55$ PL; $n 60 \mathrm{VD}$ ). PL and VD groups were similar with respect to birth anthropometry, infant feeding and care practices (Table 1) and maternal characteristics (see online supplementary material, Supplemental Table 1). Characteristics of infants in the 'subset' sample were similar to the 'full sample' (Table 1). There were no significant differences between infants included in the present study and those lost to follow-up (data not shown).

\section{Effect of prenatal vitamin $D$ supplementation on infant and maternal 25-bydroxyvitamin $D$}

In primary cross-sectional analyses ('full sample' analyses), infant mean 25(OH)D differed significantly between VD and PL groups at $<1$ month of age but was similar thereafter (Table 2). In the PL group, infant 25(OH)D increased significantly with age (Fig. 1) and the proportion of infants considered vitamin D deficient $(<30 \mathrm{nmol} / \mathrm{l})$ declined from the neonatal period to 6 months (Table 2). The rate of change in infant $25(\mathrm{OH}) \mathrm{D}$ with age was not statistically significantly different between VD and PL beyond 2 months of age (Fig. 1). Prenatal vitamin D supplementation significantly increased maternal $25(\mathrm{OH}) \mathrm{D}$ at delivery (VD ( $n$ 58) $v$. PL ( $n$ 48), mean (sD): 134 (31) nmol/l $v .37(18) \mathrm{nmol} / \mathrm{l} ; P<0.001)$, as reported previously for the complete AViDD trial cohort ${ }^{(12)}$. Maternal 25(OH)D at 2 months postpartum remained significantly higher in the VD (mean (SD): 62 (15) nmol/l; $n$ 27) $v$. PL group (mean (sD): 38 (16) nmol/1; $P<0.001 ; n$ 22); yet the difference was attenuated by 4 months postpartum (VD ( $n$ 27) v. PL ( $n$ 28), mean (SD): 55 (16) nmol/l v. 47 (16) $\mathrm{nmol} / \mathrm{l} ; P=0 \cdot 06)$.

Maternal 25(OH)D at delivery was associated with infant $25(\mathrm{OH}) \mathrm{D}$ up to 2 months of age, but not thereafter (Fig. 2A). Cord 25(OH)D significantly predicted infant $25(\mathrm{OH}) \mathrm{D}$ only at $<1$ month of age (Fig. 2B). Maternal postpartum 25(OH)D was associated with concurrent infant $25(\mathrm{OH}) \mathrm{D}$ at 2 months $(0.47$ (95\% CI $0 \cdot 16,0.78)$ $\mathrm{nmol} / \mathrm{l} ; P=0.003 ; n 48)$ and 4 months of age $(0.44$ (95\% CI $0.03,0.84) \mathrm{nmol} / \mathrm{l} ; P=0.035 ; n 50)$. Adjusting for maternal postpartum $25(\mathrm{OH}) \mathrm{D}$ substantially attenuated the association 


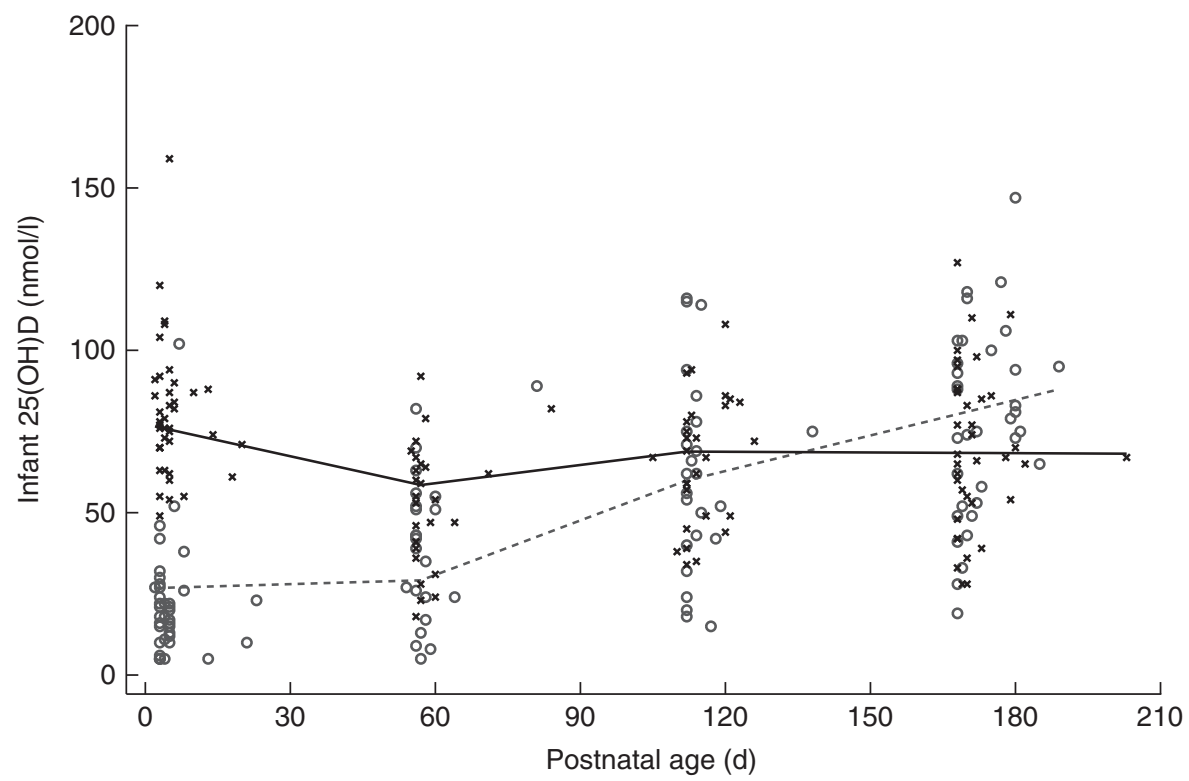

Fig. 1 Association between infant 25-hydroxyvitamin D concentration $(25(\mathrm{OH}) \mathrm{D})$ and postnatal age during the first 6 months $(n 115$; 252 observations) by supplementation group: $\circ$, placebo, observed; - - - - - placebo, predicted; $\times$, vitamin $\mathrm{D}$, observed; $\longrightarrow$, vitamin D, predicted. Among infants in the placebo group, mean change in infant $25(\mathrm{OH}) \mathrm{D}$ was $8.6(95 \% \mathrm{Cl} 3.4,13.8) \mathrm{nmol} / \mathrm{l} \mathrm{per}$ month in the first 2 months of age, as compared with a significant decrease among infants in the vitamin D group (-16.3 (95\% Cl $-22.1,-10.6) \mathrm{nmol} / \mathrm{l}$ per month; $P<0.001)$. Antenatal Vitamin $\mathrm{D}$ in Dhaka (AViDD) trial $\left(23^{\circ} \mathrm{N}\right)$, Bangladesh

between maternal delivery and infant $25(\mathrm{OH}) \mathrm{D}$ at 2 months of age (unadjusted association $=0.15(95 \%$ CI $0 \cdot 02,0.27)$ $\mathrm{nmol} / \mathrm{l}(P=0 \cdot 02 ; n$ 45) $v$. adjusted association $=0.03(95 \% \mathrm{CI}$ $-0 \cdot 01,0 \cdot 02) \mathrm{nmol} / \mathrm{l}(P=0.74 ; n$ 45)).

\section{Association of postnatal factors with infant 25-bydroxyvitamin $D$}

Infant $25(\mathrm{OH}) \mathrm{D}$ was strongly associated with age in longitudinal 'subset' analyses (Table 3). Infant 25(OH)D also demonstrated a linear association with calendar day of serum collection from mid-December to September of the following year (data not shown). This association was partially confounded by infant age (Table 3; online supplementary material, Supplemental Fig. 3A); however, when data were stratified by age categories, there was evidence of a seasonby-age interaction, whereby $25(\mathrm{OH}) \mathrm{D}$ increased by $5.2(95 \%$ CI $2 \cdot 0,8.5) \mathrm{nmol} / 1$ per month $(P=0.002)$ between January and August among 4-month-olds, but there were no significant calendar day-25(OH)D associations in the other age strata (online supplementary material, Supplemental Fig. 3B). Overall, mean infant $25(\mathrm{OH}) \mathrm{D}$ was higher with formula-feeding ( $v$. no reported formula use) and lower with exclusive breast-feeding, but the latter association was confounded by age (Table 3). Formula use was significantly associated with higher infant $25(\mathrm{OH}) \mathrm{D}$ with adjustment for age (Table 3). However, the rate of rise (i.e. slope) of $25(\mathrm{OH}) \mathrm{D}$ with age appeared similar in the context of formula use and exclusive breast-feeding (online supplementary material, Supplemental Fig. 4); and there was no significant statistical interaction between formula use (or exclusive breast-feeding) and age (Table 3).

\section{Discussion}

High-dose maternal vitamin D supplementation (875 $\mathrm{g}$ (35000 IU)/week) during the third trimester of pregnancy significantly ameliorated vitamin D status among infants in the first month of life, but the effect was attenuated by 2 months of age. The between-group mean difference of $\sim 12 \mathrm{nmol} / \mathrm{l}$ at 2 months was not statistically significant ( $P=0.05$ ) but could be clinically meaningful ( 0.6 SD units difference). We are therefore cautious not to interpret this as evidence of a lack of difference given that the power to detect a statistically significant difference of $\sim 12 \mathrm{nmol} / 1$ was only $49 \%$ (post boc power calculation). Vitamin D status was more convincingly similar among infants in the PL and VD groups by 4 months of age and thus we can reasonably conclude that a residual effect of prenatal vitamin D supplementation on infant postnatal vitamin $\mathrm{D}$ status may persist up to 2 months but is absent by 4 months postnatal age.

These findings from a randomized placebo-controlled trial provide strong evidence of the critical influence of maternal prenatal vitamin D status on infant vitamin D status during the neonatal period. Previous knowledge about this relationship was based on observational data $^{(24,25)}$. For example, 25(OH)D in unsupplemented infants born to vitamin D-replete mothers in Finland decreased from $\sim 50 \mathrm{nmol} / 1$ at birth to $<25 \mathrm{nmol} / 1$ by 8 weeks of age ${ }^{(25)}$, a finding that has been interpreted as evidence that the prenatal contribution to infant vitamin D status is limited to the first 2 months of life ${ }^{(16)}$, consistent with the present trial. Previous trials of maternal supplementation with $10 \mu \mathrm{g}$ (400 IU) vitamin D daily starting in 

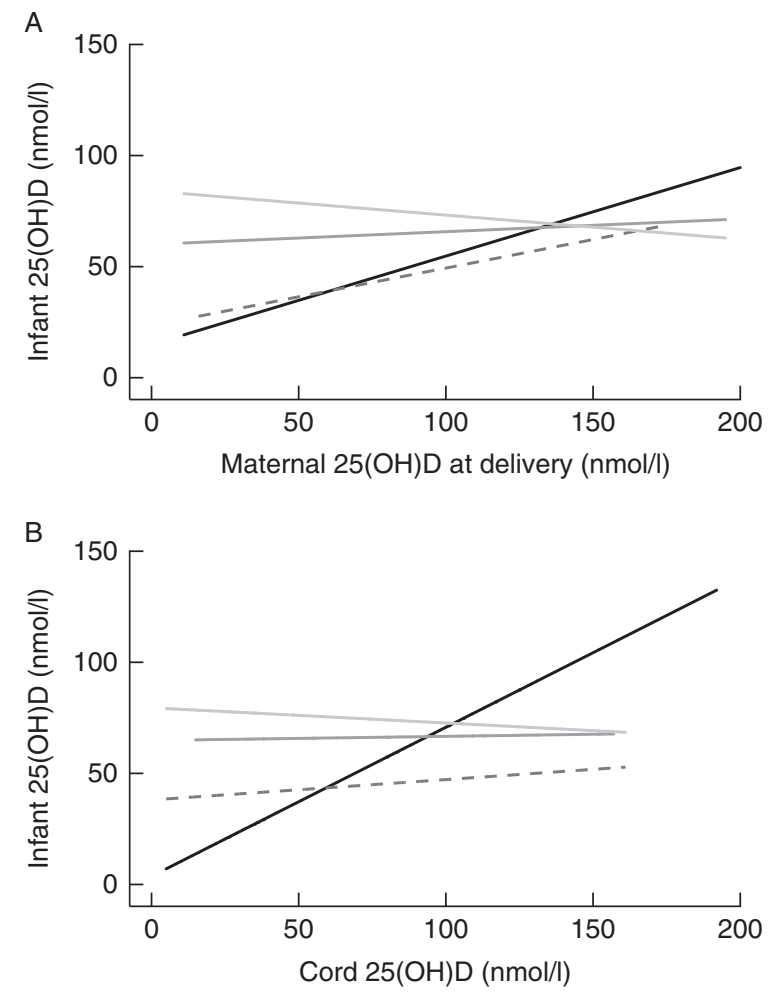

Fig. 2 Association between infant 25-hydroxyvitamin D concentration $(25(\mathrm{OH}) \mathrm{D})$ and maternal $25(\mathrm{OH}) \mathrm{D}$ at delivery (A) and cord 25(OH)D (B) by infant age: — , <1 month, predicted; --.--, 2 months, predicted; —-, 4 months, predicted; -6 months, predicted. (A) Prenatal maternal 25(OH)D (n 107; 234 observations) was significantly associated with infant 25(OH)D within the first 2 months of infancy, but not at 4 and 6 months of age. (B) Cord $25(\mathrm{OH}) \mathrm{D}$ (n 109; 238 observations) was significantly associated with infant $25(\mathrm{OH}) \mathrm{D}$ at $<1$ month of age, but not in older age strata. Antenatal Vitamin D in Dhaka (AViDD) trial $\left(23^{\circ} \mathrm{N}\right)$, Bangladesh

week 12 of pregnancy until delivery ${ }^{(17)}$ or a bolus dose of $2500 \mu \mathrm{g}$ (100000 IU) vitamin D in month 6 or 7 of pregnancy ${ }^{(18)}$ showed significant increases in infant $25(\mathrm{OH}) \mathrm{D}$; however, infant follow-up in those studies was limited to the first week of life. Other trials have conflated the effects of pre- and postnatal maternal/infant vitamin D supplementation ${ }^{(19,26-28)}$. Therefore, the present findings are new evidence of robust but short-term postnatal effects of prenatal supplementation on infant vitamin D status.

The age-associated increase in $25(\mathrm{OH}) \mathrm{D}$ during early infancy in the present longitudinal study in Dhaka corroborates our previous findings in a cross-sectional study in a rural region of Bangladesh ${ }^{(11)}$. Longitudinal studies in several countries (Korea, United Arab Emirates, southern and northern USA, New Zealand) have demonstrated a similar pattern of an early increase in 25(OH)D among breast-fed infants not receiving vitamin D supplements ${ }^{(8,19-21,29)}$. Increases in infant $25(\mathrm{OH}) \mathrm{D}$ in the first few months of life may be attributed to fortified infant formula or vitamin $\mathrm{D}$ supplementation $(10 \mu \mathrm{g}$ (400 IU)/d). In Canada and
Finland, infant vitamin D supplementation initiated in the early postnatal period has been shown to gradually increase $25(\mathrm{OH}) \mathrm{D}$ levels among breast-fed infants within the first 6 months of life $\mathrm{e}^{(30,31)}$. Notably, the increase in $25(\mathrm{OH}) \mathrm{D}$ in Canadian infants receiving $10 \mu \mathrm{g}$ (400 IU)/d, to an attained mean $25(\mathrm{OH}) \mathrm{D}$ of $\sim 75 \mathrm{nmol} / \mathrm{l}^{(30)}$, approximately mirrored the pattern observed in the Bangladeshi infants in the present study, who were not receiving supplements.

We explored several potential postnatal determinants of infant vitamin D status to explain the rise in infant $25(\mathrm{OH}) \mathrm{D}$ from birth to 6 months. There was a significant increase in $25(\mathrm{OH}) \mathrm{D}$ from winter to summer, but this did not adequately explain the age-related rise in infant $25(\mathrm{OH}) \mathrm{D}$. The strong correlation between age and calendar day in the present study (due to births of enrolled infants occurring during only part of the calendar year), however, limited our ability to fully separate the effects of age and season. Specker et al. attributed the age-associated rise in $25(\mathrm{OH}) \mathrm{D}$ to higher UV exposure in older infants ${ }^{(32)}$. Although deliberately exposing infants to sunlight, a custom that is often practised in South $\mathrm{Asia}^{(33,34)}$, may have contributed to cutaneous synthesis of vitamin D, self-reported sun exposure-related practices explained little variance in infant $25(\mathrm{OH}) \mathrm{D}$ in age-adjusted analyses in the present study.

As expected, 25(OH)D was consistently higher among infants who had recently received formula (assumed to be vitamin D-fortified). However, we had anticipated that formula use would lead to a progressive increase in $25(\mathrm{OH}) \mathrm{D}$ over time relative to exclusive breast-feeding (i.e. divergence of the $25(\mathrm{OH}) \mathrm{D}-$ age slopes). Instead, we observed that the rate of rise in infant $25(\mathrm{OH}) \mathrm{D}$ with age was similar among infants who were exclusively breast-fed and those who had received formula, suggesting that the increase in infant $25(\mathrm{OH}) \mathrm{D}$ with age was not completely attributable to vitamin D-fortified formula or complementary foods alone. This finding suggests that the effect of formula-feeding on $25(\mathrm{OH}) \mathrm{D}$ was apparent very early in infancy (i.e. by about 2 months of age) and that other factors contributing to the ongoing rise in $25(\mathrm{OH}) \mathrm{D}$ up to 6 months of age were similarly operational among infants who did and did not receive formula. Interestingly, we found that the association between prenatal maternal and infant 2-month 25(OH)D was nearly completely accounted for by maternal postpartum $25(\mathrm{OH}) \mathrm{D}$ at 2 months. Moreover, cord 25(OH)D was not associated with infant $25(\mathrm{OH}) \mathrm{D}$ beyond the first month of life. These findings suggest that the postnatal effect (to about 2 months of age) of prenatal supplementation may have been partly mediated by postpartum maternal transfer of vitamin $\mathrm{D}$ to the infant via lactation (in this nearly universally breast-fed population), rather than via prenatal endowment of fetal vitamin D stores. Continuation of maternal vitamin D supplementation in the postpartum period may therefore have an important role in influencing infant vitamin D status beyond 2 months of age ${ }^{(35)}$. 
Table 3 Associations between infant 25-hydroxyvitamin D concentration (25(OH)D) and postnatal characteristics during the first 6 months of life $\left(n\right.$ 102)†. Antenatal Vitamin D in Dhaka (AViDD) trial $\left(23^{\circ} \mathrm{N}\right)$, Bangladesh

\begin{tabular}{|c|c|c|c|c|c|c|}
\hline \multirow[b]{2}{*}{ Variable } & \multicolumn{2}{|c|}{ Unadjusted $\ddagger$} & \multicolumn{2}{|c|}{ Age-adjusted $¥, \S$} & \multicolumn{2}{|c|}{ Multivariable model $\neq, \S, \|$} \\
\hline & Estimate & $95 \% \mathrm{Cl}$ & Estimate & $95 \% \mathrm{Cl}$ & Estimate & $95 \% \mathrm{Cl}$ \\
\hline Infant age (per $30 \mathrm{~d})$ & $9 \cdot 6^{\star \star \star}$ & $8 \cdot 4,10 \cdot 8$ & $8 \cdot 0^{\star \star \star}$ & $5 \cdot 4,10 \cdot 6 \S \S$ & $6 \cdot 0^{\star * *}$ & $3 \cdot 5,8 \cdot 6$ \\
\hline Calendar day (per $30 \mathrm{~d}$ ) & $8 \cdot 2^{\star \star \star}$ & $6 \cdot 8,9 \cdot 6$ & $1 \cdot 7$ & $-0.9,4.4$ & $5 \cdot 1^{\star \star}$ & $1.5,8.7$ \\
\hline Exclusively breast-fed $\boldsymbol{\eta}$ & & & & & & \\
\hline (Ref.: Not exclusively breast-fed) & $-26 \cdot 1^{\star \star \star}$ & $-34 \cdot 2,-18 \cdot 0$ & $-6 \cdot 1$ & $-14 \cdot 7,2 \cdot 5$ & - & - \\
\hline $\begin{array}{l}\text { Formula use } \\
\text { (Ref.: No formula use) }\end{array}$ & $30 \cdot 2^{\star * *}$ & $21 \cdot 5,39$ & $13 \cdot 4^{\star \star}$ & $3 \cdot 8,23 \cdot 0|| I \mid$ & $13 \cdot 7^{\star \star}$ & $4 \cdot 0,23 \cdot 3$ \\
\hline Swaddlingף,†† & & & & & & \\
\hline $\begin{array}{l}\text { Never/rarely } \\
\text { Sometimes } \\
\text { Always/usually }\end{array}$ & $\begin{array}{c}\text { Ref. } \\
-11 \cdot 9^{\star} \\
-37 \cdot 4^{\star \star \star}\end{array}$ & $\begin{array}{l}-22 \cdot 5,-1 \cdot 3 \\
-45 \cdot 1,-29 \cdot 6\end{array}$ & $\begin{array}{l}\text { Ref. } \\
2 \cdot 3 \\
-5 \cdot 1\end{array}$ & $\begin{array}{l}-7 \cdot 0,11 \cdot 6 \\
-16 \cdot 8,6 \cdot 6\end{array}$ & $\begin{array}{l}- \\
-\end{array}$ & $\begin{array}{l}- \\
-\end{array}$ \\
\hline Infant exposure to sunlight & & & & & & \\
\hline Usually avoids sun & Ref. & & & & & \\
\hline No specific habit & $5 \cdot 7$ & $-11 \cdot 8,23 \cdot 2$ & - & - & - & - \\
\hline Prefers sun exposure & 11.4 & $-5 \cdot 3,28 \cdot 0$ & - & - & - & - \\
\hline Highest level of education & & & & & & \\
\hline Primary school ( $<8$ years) & Ref. & & & & & \\
\hline High school incomplete ( $\geq 8$ to $<12$ years) & $-8 \cdot 1$ & $-18 \cdot 9,2 \cdot 6$ & - & - & - & - \\
\hline High school complete ( $\geq 12$ years) & $6 \cdot 0$ & $-8 \cdot 2,20 \cdot 2$ & - & - & - & - \\
\hline Maternal age (years) & -0.3 & $-1.5,0.9$ & - & - & - & - \\
\hline Gravidity, no. of pregnancies & 0.2 & $-6 \cdot 5,7 \cdot 0$ & - & - & - & - \\
\hline Parity, no. of deliveries & 1.0 & $-5 \cdot 7,7 \cdot 7$ & - & - & - & - \\
\hline Maternal height (cm) & 0.7 & $-0.1,1.5$ & - & - & - & - \\
\hline
\end{tabular}

Ref., reference category.

${ }^{\star} P<0.05,{ }^{\star \star} P<0.01,{ }^{\star \star \star} P<0.001$.

†See Methods ('Statistical analysis' subsection) for details regarding the subset of observations considered to be uninfluenced by prenatal maternal vitamin $D$ supplementation.

$\ddagger$ Generalized estimating equations (GEE) were used to account for within-subject correlations in all models. Effect estimates are $\beta$ coefficients (95\% CI) and can be interpreted as the mean difference in $25(\mathrm{OH}) \mathrm{D}$ given a one unit increase in the explanatory variable.

§Infant age was treated as a continuous variable, scaled by $30 \mathrm{~d}$.

IIMultivariable model includes an age-by-calendar day continuous interaction term $(-0.79(95 \% \mathrm{Cl}-1.5,-0.1) \mathrm{nmol} / \mathrm{l} ; P<0.05)$, in addition to the covariates presented. Formula use-by-age interaction term was not statistically significant and not included in the final model.

In 101; 177 observations. Data on exclusive breast-feeding, formula use, swaddling and sunlight exposure practices were missing for ten observations. $\dagger \uparrow$ Swaddling practice and sunlight exposure preference did not significantly modify the association between calendar day and $25(\mathrm{OH}) \mathrm{D}$ (data not shown). ¥¥Reported maternal preference with respect to the deliberate exposure of the infant to sunlight ( $n$ 101; 175 observations).

$\S \S$ Adjusted for calendar day ( $n$ 102; 187 observations).

IIIIAdjustment for formula use did not attenuate the association between age and infant $25(\mathrm{OH}) \mathrm{D}(8.8(95 \% \mathrm{Cl} 0.7,10.2) \mathrm{nmol} / \mathrm{l}$ per $30 \mathrm{~d}$; $P<0.001)$.

The findings of the present study must be interpreted in the context of its limitations. As described above, the small sample size limited the power to detect significant associations that may otherwise have been apparent given a larger study sample. The generalizability of the findings regarding the age-related rise in $25(\mathrm{OH}) \mathrm{D}$ and potential explanatory factors may be limited to communities with similar sun exposure practices, dietary patterns and environmental conditions. The rise in infant $25(\mathrm{OH}) \mathrm{D}$ with age was not fully explained by the postnatal factors that we analysed, suggesting other unidentified variables may be important. For example, we did not collect ancillary biochemical or physiological data (e.g. hepatic or renal function) that may have indicated whether organ maturation contributed to changes in infant $25(\mathrm{OH}) \mathrm{D}$ with age. Lifestyle and environmental determinants of UV exposure likely contributed to maternal and infant vitamin D status in the postpartum period; however, precisely quantifying those factors was beyond the scope of the study. Measurement error associated with indicators used to measure postnatal maternal and infant characteristics, such as sunlight exposure, may have attenuated associations with infant 25(OH)D. Sparse data at $\leq 2$ months of age and imprecision in ascertainment of infant feeding practices likely limited our ability to clearly characterize the early effect of formula consumption on infant $25(\mathrm{OH}) \mathrm{D}$. It is also possible that the maternal decision regarding formula-feeding was a surrogate marker of other unmeasured characteristics that influenced vitamin D status from early in infancy. We had limited data about specific complementary foods that were introduced; however, overall, there was minimal use of complementary foods before 6 months of age and vitamin D-fortified foods other than formula are infrequently consumed in lower-income households in Bangladesh. An important limitation was that we did not consider C3-epi-25(OH)D separately from total $25(\mathrm{OH}) \mathrm{D}$ in this analysis; the $\mathrm{C} 3$-epimer of $25(\mathrm{OH}) \mathrm{D}$ may have a unique physiological role, especially in early infancy when it is relatively abundant ${ }^{(36)}$.

\section{Conclusion}

The present study confirmed the influence of maternal prenatal vitamin D intake on early infant vitamin D status. 
Prenatal vitamin D supplementation is an efficacious strategy for promoting infant vitamin D sufficiency in the first month of life when the risk of deficiency is highest. Unsupplemented breast-fed infants born to vitamin D-deficient mothers in Bangladesh attained 25(OH)D concentrations by 6 months of age that were comparable to those of vitamin D-supplemented infants at northern latitudes. These findings suggest that in considering the potential benefits of postnatal infant vitamin D supplementation in settings such as Bangladesh, the increase in average $25(\mathrm{OH}) \mathrm{D}$ with age in the apparent absence of infant vitamin D supplements should be acknowledged. Future research should aim to address the effect of prenatal maternal vitamin D supplementation on health outcomes in a larger and more diverse cohort of infants with longer duration of follow-up and more comprehensive data collection related to factors that may explain the postnatal dynamics of vitamin D status.

\section{Acknowledgements}

Acknowledgements: The authors appreciate the efforts of staff and collaborating investigators at the International Centre for Diarrheal Disease Research, Bangladesh (icddr, b) and Shimantik in Dhaka, including Drs Shams El Arifeen and Rubhana Raqib; and thank Khosrow Adeli, Warren Walsh and Mehrdad Yazdanpanah (The Hospital for Sick Children, Toronto, Canada) for measurement of 25(OH)D concentrations. Financial support: The intervention trial was funded by The Thrasher Fund (Salt Lake City, UT, USA) and the follow-up study was funded by the Department of Paediatrics, The Hospital for Sick Children. N.P. was supported through a studentship by the Research and Training Competition (Restracomp), The Hospital for Sick Children Foundation Student Scholarship Program. The funders had no role in the design, analysis or writing of this article. Conflict of interest: None. Authorship: D.E.R., A.A.M. and A.H.B. designed the AViDD trial; A.A.M. supervised data collection; N.P. and D.E.R. performed the data analyses and prepared the manuscript. All authors read and approved the final manuscript. Ethics of buman subject participation: This study was conducted according to the guidelines laid down in the Declaration of Helsinki and all procedures involving human subjects/ patients were approved by the research ethics boards of icddr,b, the Johns Hopkins Bloomberg School of Public Health (Baltimore, MD, USA) and The Hospital for Sick Children. Written informed consent was obtained from all participants.

\section{Supplementary material}

To view supplementary material for this article, please visit http://dx.doi.org/10.1017/S1368980015003092

\section{References}

1. Toaima FH \& Ansari KA (2009) Nineteen cases of symptomatic neonatal hypocalcemia secondary to vitamin D deficiency: a 2-year study. J Trop Pediatr 56, 108-110.

2. Zipitis CS \& Akobeng AK (2008) Vitamin D supplementation in early childhood and risk of type 1 diabetes: a systematic review and meta-analysis. Arch Dis Child 93, 512-517.

3. Roth DE, Perumal N, Al Mahmud A et al. (2013) Maternal vitamin $\mathrm{D}_{3}$ supplementation during the third trimester of pregnancy: effects on infant growth in a longitudinal followup study in Bangladesh. J Pediatr 163, 1605-1611.

4. Institute of Medicine (2010) Dietary Reference Ranges for Calcium and Vitamin D. Washington, DC: National Academies Press.

5. Health Canada, Canadian Paediatric Society, Dietitians of Canada \& Breastfeeding Committee for Canada (2014) Nutrition for healthy term infants: Recommendations from six to 24 months. http://www.hc-sc.gc.ca/fn-an/nutrition/infantnourisson/recom/index-eng.php\#a3 (accessed October 2015).

6. Scientific Advisory Committee on Nutrition (2007) Update on Vitamin D: Position Statement by the Scientific Advisory Committee on Vitamin D. London: Food Standards Agency and Department of Health.

7. Nguema-Asseko B, Ganga-Zandzou PS, Ovono F et al. (2005) Vitamin D status in Gabonese children. Arch Pediatr 12, 1587-1590.

8. Ponnapakkam T, Bradford E \& Gensure R (2010) A treatment trial of vitamin $D$ supplementation in breast-fed infants: universal supplementation is not necessary for rickets prevention in southern Louisiana. Clin Pediatr $\mathbf{4 9}$, 1053-1060.

9. Jain V, Gupta N, Kalaivani M et al. (2011) Vitamin D deficiency in healthy breastfed term infants at 3 months \& their mothers in India: seasonal variation \& determinants. Indian J Med Res 133, 267-273.

10. Kumar GT, Sachdev HS, Chellani H et al. (2011) Effect of weekly vitamin D supplements on mortality, morbidity, and growth of low birthweight term infants in India up to age 6 months: randomised controlled trial. BMJ 342, d2975.

11. Roth DE, Shah MR, Black RE et al. (2010) Vitamin D status of infants in northeastern rural Bangladesh: preliminary observations and a review of potential determinants. $J$ Health Popul Nutr 28, 458-469.

12. Roth DE, Al Mahmud A, Raqib R et al. (2013) Randomized placebo-controlled trial of high-dose prenatal third-trimester vitamin $\mathrm{D}_{3}$ supplementation in Bangladesh: the AViDD trial. Nutr J 12, 47.

13. Atiq M, Suria A, Nizami SQ et al. (1998) Maternal vitamin-D deficiency in Pakistan. Acta Obstet Gynecol Scand 77, 970-973.

14. Hossain N, Khanani R, Hussain-Kanani F et al. (2011) High prevalence of vitamin D deficiency in Pakistani mothers and their newborns. Int J Gynecol Obstet 112, 229-233.

15. Balasubramanian S (2011) Vitamin D deficiency in breastfed infants \& the need for routine vitamin D supplementation. Indian J Med Res 133, 250-252.

16. Salle BL, Delvin EE, Lapillonne A et al. (2000) Perinatal metabolism of vitamin D. Am J Clin Nutr 71, 5 Suppl., 1317S-1324S.

17. Cockburn F, Belton NR, Purvis RJ et al. (1980) Maternal vitamin $\mathrm{D}$ intake and mineral metabolism in mothers and their newborn infants. Br Med J 281, 11-14.

18. Zeghoud F, Garabedian M, Jardel A et al. (1988) Single oral administration of vitamin $\mathrm{D}_{3}(100,000 \mathrm{IU})$ to pregnant women. Effects on calcium and vitamin D status of their newborns. J Gynecol Obstet Biol Reprod (Paris) 17, 1099-1105.

19. Grant CC, Stewart AW, Scragg R et al. (2014) Vitamin D during pregnancy and infancy and infant serum 25-hydroxyvitamin D concentration. Pediatrics 133, e143-e153. 
20. Ziegler EE, Hollis BW, Nelson SE et al. (2006) Vitamin D deficiency in breastfed infants in Iowa. Pediatrics $\mathbf{1 1 8}$ 603-610.

21. Narchi H, Kochiyil J, Zayed R et al. (2011) Longitudinal study of vitamin D status in the 1st 6 months of life. Ann Trop Paediatr 31, 225-230.

22. Amukele TK, Soko D, Katundu P et al. (2013) Vitamin D levels in Malawian infants from birth to 24 months. Arch Dis Child 98, 180-183.

23. Roth DE, Al Mahmud A, Raqib R et al. (2013) Pharmacokinetics of high-dose weekly oral vitamin $\mathrm{D}_{3}$ supplementation during the third trimester of pregnancy in Dhaka, Bangladesh. Nutrients 5, 788-810.

24. Hoogenboezem T, Degenhart HJ, De Muinck KeizerSchrama SMPF et al. (1989) Vitamin D metabolism in breast-fed infants and their mothers. Pediatr Res $\mathbf{2 5}$, 623-628.

25. Birkbeck JA \& Scott HF (1980) 25-Hydroxycholecalciferol serum levels in breast-fed infants. Arch Dis Child 55, 691-695.

26. Ala-Houhala M, Koskinen T, Terho A et al. (1986) Maternal compared with infant vitamin D supplementation. Arch Dis Child 61, 1159-1163.

27. Ala-Houhala M (1985) 25-Hydroxyvitamin D levels during breast-feeding with or without maternal or infantile supplementation of vitamin D. J Pediatr Gastroenterol Nutr 4, 220-226.

28. VioStreym S, Kristine Moller U, Rejnmark L et al. (2013) Maternal and infant vitamin $D$ status during the first
9 months of infant life - a cohort study. Eur J Clin Nutr 67, 1022-1028.

29. Kim M, Na B, No S et al. (2010) Nutritional status of vitamin D and the effect of vitamin D supplementation in Korean breast-fed infants. J Korean Med Sci 25, 83-89.

30. Gallo S, Comeau K, Vanstone C et al. (2013) Effect of different dosages of oral vitamin D supplementation on vitamin $D$ status in healthy, breastfed infants: a randomized trial. JAMA 309, 1785-1792.

31. Holmlund-Suila E, Viljakainen H, Hytinantti T et al. (2012) High-dose vitamin D intervention in infants: effects on vitamin D status, calcium homeostasis, and bone strength. J Clin Endocrinol Metab 97, 4139-4147.

32. Specker BL, Valanis B, Hertzberg V et al. (1985) Sunshine exposure and serum 25-hydroxyvitamin D concentrations in exclusively breast-fed infants. J Pediatr 107, 372-376.

33. Balasubramanian S \& Ganesh R (2008) Vitamin D deficiency in exclusively breast-fed infants. Indian J Med Res 127, 250-255.

34. Winch PJ, Alam MA, Akther A et al. (2005) Local understandings of vulnerability and protection during the neonatal period in Sylhet district, Bangladesh: a qualitative study. Lancet 366, 478-485.

35. Taylor SN, Wagner CL \& Hollis BW (2009) Vitamin D deficiency in pregnancy and lactation and health consequences. Clin Rev Bone Min Metab 7, 42-51.

36. Bailey D, Veljkovic K, Yazdanpanah M et al. (2013) Analytical measurement and clinical relevance of vitamin $\mathrm{D}_{3}$ C3-epimer. Clin Biochem 46, 190-196. 